\title{
Oceans apart: conservation models for two temperate penguin species shaped by the marine environment
}

\author{
P. Dee Boersma ${ }^{1, *}$, Ginger A. Rebstock ${ }^{1}$, David L. Stokes ${ }^{2}$, P. Majluf ${ }^{3}$ \\ ${ }^{1}$ Department of Biology, Box 351800, University of Washington, Seattle, Washington 98195-1800, USA \\ ${ }^{2}$ Department of Interdisciplinary Arts and Sciences, Box 358530, University of Washington Bothell, Bothell, \\ Washington 98011, USA \\ ${ }^{3}$ Unidad de Biologia de la Conservacion, Universidad Cayetano Heredia, Armedariz 445, Lima 18, Peru
}

\begin{abstract}
Oceanographic productivity patterns in the breeding areas of Magellanic penguins Spheniscus magellanicus in the Atlantic differ from those of Humboldt penguins S. humboldti in the Pacific. We used satellite telemetry to compare foraging trips between 2 Humboldt penguin females with chicks and 44 Magellanic penguin females with eggs or chicks. The Humboldt penguins took trips of short duration and distance, with fewer than $10 \%$ of locations $>25 \mathrm{~km}$ from the colony. Magellanic penguins traveled longer and more variable distances. Only $24 \%$ of locations during chick rearing were within $25 \mathrm{~km}$ of the colony; all 8 incubation trips reached distances greater than $100 \mathrm{~km}$. Among Magellanic penguins, foraging trip duration was significantly correlated with distance from the colony during all stages of the breeding season (incubation $\mathrm{r}^{2}=0.66$; early chick $\mathrm{r}^{2}=0.75$; late chick $\mathrm{r}^{2}=0.91$ ). For each hour of trip duration, penguins ranged nearly $1 \mathrm{~km}$ farther from the colony. For the 2 Humboldt females, trip duration was correlated with maximum distance from the colony for one female but not the other, whose trip duration varied little. Trip duration for Magellanic penguins determined by nest checks was correlated with duration determined by satellite telemetry $\left(\mathrm{r}^{2}=0.96\right)$, making nest checks a potentially inexpensive and minimally disturbing estimator of foraging trip distance and changing food availability. The large difference in foraging distance between the species reflects the distribution of productivity in their foraging areas and shows that protecting the species requires conservation models that are effective on different spatial scales.
\end{abstract}

KEY WORDS: Spheniscus magellanicus $\cdot$ Magellanic penguin $\cdot$ Spheniscus humboldti $\cdot$ Humboldt penguin $\cdot$ Foraging range $\cdot$ Conservation model $\cdot$ Marine protected area $\cdot$ Management zone

\section{INTRODUCTION}

Humboldt penguins Spheniscus humboldti and Magellanic penguins $S$. magellanicus are closely related South American species that are similar in size, breeding biology, and diet (Davis \& Renner 2003). Both species are currently of conservation concern, and successful conservation of these species depends on their protection at sea. Humboldt penguins have declined throughout their range (Luna-Jorquera et al. 2000), and the species has been designated as vulnerable (IUCN 2003). Magellanic penguins, although more numerous at present, are also declining and are nearthreatened (IUCN 2003). Human activities are a major cause of both species' imperilment. Humboldt penguins regularly suffer adult mortality through by-catch in gillnets (Simeone et al. 1999, Majluf et al. 2002), along with historical loss of nesting habitat from guano harvest (Paredes \& Zavalaga 2001). Petroleum pollution and by-catch also threaten Magellanic penguins (Boersma et al. 1990, García-Borboroglu et al. 2006). Both species are also probably negatively affected by prey reduction from commercial fishing (Crawford \& Jahncke 1999) and climate anomalies. 
Although similar in many ways, the 2 species inhabit very different oceanographic environments. The bulk of the Magellanic penguin population breeds in coastal Argentina along the Patagonian shelf, one of the broadest continental shelves in the world. The shelf break (200 $\mathrm{m}$ isobath) is more than $400 \mathrm{~km}$ from shore at $44^{\circ} \mathrm{S}$, where the largest colony of the species is found. Productivity and prey abundance are primarily determined by widely distributed tidal and estuarine fronts, which vary seasonally (Acha et al. 2004). By contrast, Humboldt penguins occur in Peru and Chile, along a relatively fixed region of coastal upwelling where the continental shelf is extremely narrow and productivity is usually high except during El Niño years (Acha et al. 2004). The surface chlorophyll maximum at $15^{\circ} \mathrm{S}$ off Peru occurs at approximately $18 \mathrm{~km}$ offshore, with high levels of production in upwelling plumes that drift up to $60 \mathrm{~km}$ offshore (MacIsaac et al. 1985). At Punta San Juan, the site of the largest Humboldt penguin colony in Peru (Paredes et al. 2002), the shelf is even narrower, $<10 \mathrm{~km}$. These differences in the marine environment are likely to influence the 2 species' foraging patterns in ways that have important implications for their conservation.

Marine reserves and marine protected areas (MPAs; i.e. fixed areas that exclude some human activities) and more extensive and flexible marine management zones (e.g. time-area closures) are the primary models for marine biodiversity conservation (Hyrenbach et al. 2000). The suitability of these models depends on the requirements of the species to be protected. Species that occur in predictable and small areas may be effectively protected by MPAs. Conversely, species that are wide-ranging or inhabit variable systems are more appropriately protected by marine zoning because of the large extent and flexibility of the required protective measures (Boersma \& Parrish 1999, Hyrenbach et al. 2000). Regardless of which of these models is appropriate for the conservation of particular species, the design of effective conservation measures requires an understanding of the species' pattern of use of the marine environment.

In recent years, miniaturized monitoring technology (satellite transmitters, GPS, time-depth recorders) has permitted increasingly detailed descriptions of Magellanic penguin behavior at sea. The extent and variability of foraging areas revealed by these data indicate that MPAs are probably too limited to protect this species, and that marine management zones are needed (Boersma \& Parrish 1999). Less is known about the foraging locations and behaviors of the more endangered Humboldt penguins, with only limited satellite-tracking data on this species to date (Culik et al. 2000 and references therein).
Using satellite telemetry, we tracked the foraging trips of 2 female Humboldt penguins that were raising small chicks and 44 female Magellanic penguins with eggs or chicks in 5 breeding seasons. We used the more extensive and precise Magellanic penguin tracking data to develop a model for determining foraging distance based on the duration of the birds' absence from the nest. Trip duration is an inexpensive and tractable means to determine the maximum distance that penguins forage from the colony, and is a valuable tool for the management and conservation of penguins.

\section{MATERIALS AND METHODS}

We used satellite tracking to determine the at-sea locations of Humboldt penguins during the early-chick stage of the breeding season in 2000 (for tracking methods see Stokes \& Boersma 1999, Boersma et al. 2002). We tracked Magellanic penguins during the incubation, early-chick, and/or late-chick stages for 5 yr. All tracked birds were females with eggs or chicks. Satellite tags were Telonics ST-10 transmitters packaged in a pressure-resistant epoxy casting (Sirtrack). The devices weighed $96 \mathrm{~g}$ and had a cross-sectional area of $6.6 \mathrm{~cm}^{2}$. Transmitters were attached with epoxy to the feathers approximately $4 \mathrm{~cm}$ above the preen gland in the center of the lower back to minimize drag (Bannasch et al. 1994). The devices transmitted continuously at $45 \mathrm{~s}$ intervals until the batteries failed. Transmissions were received through the Service ARGOS satellite system.

Humboldt penguins. On 29 June 2000, we attached transmitters to 2 female Humboldt penguins breeding at Punta San Juan, Peru (15 $\left.22^{\prime} \mathrm{S}, 75^{\circ} 11^{\prime} \mathrm{W}\right)$, the largest colony of this species in Peru, with more than 1000 breeding pairs (Paredes et al. 2002). Female 1 weighed $3.81 \mathrm{~kg}$ and had 2 chicks approximately 4 wk old. Female 2 weighed $3.65 \mathrm{~kg}$ and had 2 chicks approximately 2 wk old.

To determine whether the penguins were present at the colony, we attached a VHF radio transmitter (15 g; Advanced Telemetry Systems) along with each satellite transmitter. During the period the devices were deployed, we monitored radio signals each morning and late afternoon from a distance of approximately $100 \mathrm{~m}$ from each bird's nest site.

The satellite tags transmitted from 29 June until 22 July, after which the signal strength decreased and position accuracy became inadequate for analysis. Because the satellites are in polar orbit and the study site is at low latitude, satellite coverage was more limited than at higher latitudes. We received a maximum of 12 locations per day, some not sufficiently accurate to 
be used for analysis (Argos location classes A, B, and Z). Prior to deployment, we placed 4 satellite tags in the open on the roof of a building at Punta San Juan to determine the frequency of satellite detection and location accuracy for the devices. In $3 \mathrm{~d}$, we received a total of 28 locations of Class 0 or better from the 4 transmitters. The mean $( \pm \mathrm{SD})$ deviation from the GPS position for locations of Class $0(n=5)$ was 2.87 $( \pm 1.2) \mathrm{km}$, and the maximum was $4.69 \mathrm{~km}$. For locations of Class 1 or better $(\mathrm{n}=23)$, mean deviation was $0.79( \pm 0.55) \mathrm{km}$, and the maximum was $2.17 \mathrm{~km}$.

Magellanic penguins. We attached transmitters to female Magellanic penguins breeding at Punta Tombo, Argentina $\left(44^{\circ} 02^{\prime} \mathrm{S}, 65^{\circ} 11^{\prime} \mathrm{W}\right)$, the largest colony of this species (Boersma et al. 1990). We tracked 44 different Magellanic penguins (2 females were each tracked in 2 different years) during 3 stages of the breeding season (Table 1). For incubation, we used only the first long foraging trip for females with eggs. For the early-chick stage, we used females with brooded chicks up to about 1 mo old, when they are fed every day to every few days (Boersma et al. 1990). After about $1 \mathrm{mo}$, chicks are left unguarded and are fed less frequently (late-chick stage; Boersma et al. 1990). We obtained more than 1 trip for most penguins during the chick-rearing stages. We visited nests of tagged birds in the morning and late afternoon each day while the devices were deployed. At each visit we recorded the identity of the birds present at the nest, determined by flipper band number, and the condition of the chicks. If both chicks had died, we replaced them with a chick from a neighboring nest. The adults accepted and fed these foster chicks.

For comparison with the Humboldt penguin foraging trips, we used Magellanic penguin foraging trips from the early-chick period of the same breeding season (1999-2000). All 4 females tracked at this time had 2 chicks less than $4 \mathrm{~d}$ old. At the time of tag attachment, Females 1 to 4 weighed $3.8,3.7,3.3$, and $4.2 \mathrm{~kg}$, respectively. We received transmissions from 24 November to 26 December $(25.3 \pm 4.9$ d per device, mean \pm $\mathrm{SD}, \mathrm{n}=4$ ) and received an average of $14.9( \pm 2.3)$ locations (all classes) per day ( $\mathrm{n}=4$ ) in Argentina, nearly twice as many as for Humboldt penguins at Punta San Juan, Peru (8.2 \pm 0.3 locations per day, $\mathrm{n}=2$ ).

Analysis. To analyze the locations of birds at sea, we used satellite telemetry locations of Class 0 (no predicted accuracy; see above) and Class 1-3 (1 km estimated accuracy or better). Because of the possible inaccu- racy of locations (maximum deviation in our bench test $=4.69 \mathrm{~km}$ ), we considered all locations within $5 \mathrm{~km}$ of the colony to be at the nest.

We defined a foraging trip as 3 consecutive locations of Class 0 or better that were more than $5 \mathrm{~km}$ from the colony. To calculate trip duration, we defined trip endpoints (i.e. returns to the nest) as either a groundbased observation of the bird at the colony, or 1 location of Class $1-3$ or 2 consecutive locations of Class 0-3 less than $5 \mathrm{~km}$ from the colony. Time of departure was defined as the midpoint between the time of the last location within $5 \mathrm{~km}$ of the colony and the time of the first location more than $5 \mathrm{~km}$ from the colony. Similarly, return time was the midpoint between the time of the last location more than $5 \mathrm{~km}$ from the colony and first location within $5 \mathrm{~km}$. For the 2 Humboldt penguins and the 4 Magellanic penguins tracked in the early-chick stage in 1999, we mapped all trips that included at least 2 at-sea locations of Class 1-3 using ArcView geographic information system software (1992-1999, ESRI). Because of the reduced precision of Class 0 locations, we used only locations of Class 1 or better for analysis of trip distances and for plotting trip paths.

We used regression analysis to characterize the relationship between foraging trip duration and foraging movements for each species within each stage of the breeding season. To model these relationships, we pooled trip data for individuals and used a repeated measures (mixed effects) model, with maximum distance from the colony as the response variable, trip duration as a continuous predictor variable, individual as a random dummy variable, and year as a factor (for Magellanic penguins). We also compared trip durations determined by different nest-check regimes (using morning checks only, evening checks

Table 1. Spheniscus magellanicus. Females ( $\mathrm{n}=44$ individuals in 46 deployments) tracked at Punta Tombo, Argentina, in 3 stages of the breeding season over 5 yr. Weight was measured at the time of transmitter deployment

\begin{tabular}{|llccc|}
\hline Season & Stage & No. females & $\begin{array}{c}\text { No. trips/female } \\
\text { mean } \pm \text { SD }\end{array}$ & $\begin{array}{c}\text { Weight (kg) } \\
\text { mean } \pm \text { SD }\end{array}$ \\
\hline $1997-98$ & Incubation & 3 & 1 & $3.76 \pm 0.32$ \\
$1998-99$ & Incubation & 2 & 1 & $3.28 \pm 0.11$ \\
$1999-00$ & Incubation & 1 & 1 & 3.35 \\
$2001-02$ & Incubation & 2 & 1 & $3.40 \pm 0.07$ \\
$1998-99$ & Early-chick & 6 & $7.2 \pm 2.48$ & $4.41 \pm 0.39$ \\
$1999-00$ & Early-chick & 4 & $5.8 \pm 2.22$ & $3.74 \pm 0.37$ \\
$2000-01$ & Early-chick & 6 & $3.3 \pm 2.07$ & $3.47 \pm 0.29$ \\
$2001-02$ & Early-chick & 4 & $6.5 \pm 1.73$ & $4.18 \pm 0.33$ \\
$1998-99$ & Late-chick & 5 & $3.6 \pm 2.61$ & $3.44 \pm 0.16$ \\
$1999-00$ & Late-chick & 2 & $5.5 \pm 2.12$ & $3.80 \pm 0.57$ \\
$2000-01$ & Late-chick & 5 & $4.8 \pm 3.49$ & $3.50 \pm 0.19$ \\
$2001-02$ & Late-chick & 6 & $6.5 \pm 4.23$ & $3.49 \pm 0.45$ \\
\hline
\end{tabular}


only, and both morning and evening checks) with satellite-determined trip durations for Magellanic penguins. Statistical methods followed Sall et al. (2005).

\section{RESULTS}

\section{Humboldt penguins}

Both of the Humboldt penguins we tracked foraged close to the colony (Fig. 1, Table 2). More than 90\% (85 of 92) of all at-sea locations we received were within $25 \mathrm{~km}$ of the colony, and approximately half (45 of 92) were within $15 \mathrm{~km}$ of the colony. More than $95 \%$ of all locations were within $20 \mathrm{~km}$ of shore (89 of 92 locations). Neither bird was ever located farther than $45 \mathrm{~km}$ from the colony or more than $30 \mathrm{~km}$ from shore (Table 2). Both birds foraged primarily south of Punta San Juan (Fig. 1), with approximately $90 \%$ of at-sea locations south of the colony (Female 1: 55 of 59 locations; Female 2: 30 of 33). Excluding Class 0 locations, none of the trips exceeded $35 \mathrm{~km}$ from the colony, and all but 2 did not exceed $25 \mathrm{~km}$ (Fig. 2). Average maximum

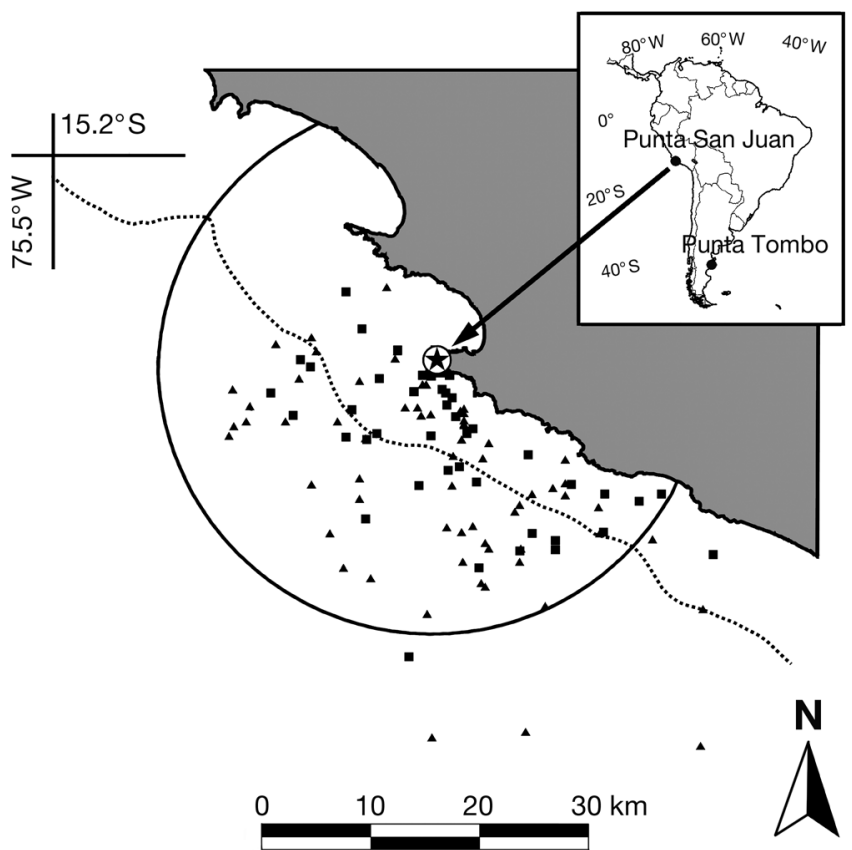

Fig. 1. Spheniscus humboldti. Locations of 2 females breeding at Punta San Juan, Peru, 29 June to 22 July 2000. Only locations of Class 0 or better are included (see text). Triangles: Female 1, squares: Female 2. Star indicates the colony at Punta San Juan. Dashed line indicates the $100 \mathrm{~m}$ isobath. Solid line indicates a $25 \mathrm{~km}$ radius distance from the colony of all foraging trips was $19.8 \mathrm{~km}(\mathrm{SD}=8.1, \mathrm{n}=12$ ) (Table 3). Trip duration was relatively uniform, with 12 of the 13 trips lasting between 24 and $48 \mathrm{~h}(29.8 \pm 6.9 \mathrm{~h})$.

Because trip distance and duration could be influenced by food demand, we expected Female 1 to take longer trips due to the greater food needs and storage capacity of her older and larger chicks. However, there was no significant difference in the trip duration (Student's $t$-test, $t_{11}=1.67, \mathrm{p}=0.12$ ) or distance from the colony $\left(t_{10}=0.64, \mathrm{p}=0.54\right)$ between the 2 birds, although trip duration was less variable for Female 2 (Female 1: $32.1 \pm 8.0 \mathrm{~h}$, coefficient of variation $[\mathrm{CV}]=0.25, \mathrm{n}=8$; Female 2: $26.0 \pm 1.0, \mathrm{CV}=0.04$, $\mathrm{n}=5$ ). The 2 birds' locations at sea overlapped extensively (Figs. 1 \& 2).

Many trips took the form of loops, where penguins did not leave and return along the same track (Fig. 2). Female 1 traveled in both clockwise $(\mathrm{n}=2)$ and counterclockwise $(n=4)$ directions, while all 3 of Female 2's trips were clockwise (Fig. 2). Where females swam in a loop close to the coast, Female 1 returned to the colony along the coast ( $\mathrm{n}=2$ trips), and Female 2 departed along the coast $(n=2)$.

\section{Magellanic penguins}

Magellanic penguins in all stages of the breeding season swam farther than Humboldt penguins during the early-chick stage. Maximum distance from the colony varied by stage $\left(F_{3,130}=156.2, \mathrm{p}<0.0001\right)$ and by year $\left(F_{4,130}=4.0, \mathrm{p}=0.004\right)$. Magellanic penguins ranged farthest during incubation $(332 \pm 140 \mathrm{~km}, \mathrm{n}=$ 8 trips) and stayed closest to the colony in the earlychick stage $(64 \pm 47 \mathrm{~km}, \mathrm{n}=96)$. They ranged intermediate distances during the late-chick stage (99 \pm $79 \mathrm{~km}, \mathrm{n}=75$ ). Trip duration also varied by stage 
$\left(F_{3,162}=158.1, \mathrm{p}<0.0001\right)$ and year $\left(F_{4,162}=3.1, \mathrm{p}=\right.$ 0.017 ), with longer trips during incubation (485 \pm $132.5 \mathrm{~h}, \mathrm{n}=8$ ) than in the chick-rearing stages (earlychick: $48 \pm 42.5 \mathrm{~h}, \mathrm{n}=112$; late-chick: $93 \pm 102.0 \mathrm{~h}$, $\mathrm{n}=92)$.

The 4 Magellanic penguins tracked in the same season and stage as the Humboldt penguins traveled much farther from their colony than did the Humboldt penguins (mean maximum distance: Humboldt = $36.5 \mathrm{~km}$, Magellanic $=156.4 \mathrm{~km} ;$ t-test, $t_{4}=5.54, \mathrm{p}=$ 0.005 ; Table 2). Maximum distance from the colony exceeded $125 \mathrm{~km}$ for the 4 Magellanic penguins, and 1 bird was recorded nearly $190 \mathrm{~km}$ from the colony. Only $25 \%$ of at-sea locations (195 of 776) were within $25 \mathrm{~km}$ of the colony and approximately half $(\mathrm{n}=400)$ were more than $65 \mathrm{~km}$ from the colony. All 4 birds were located more than $40 \mathrm{~km}$ from shore (Table 2). Locations were spread over a broad area to the east and northeast of the colony, in some cases including Golfo Nuevo, a large bay $140 \mathrm{~km}$ to the northeast of the colony (Fig. 3).

Using only locations of Class 1-3, 18 of the birds' 21 foraging trips exceeded $25 \mathrm{~km}$ from the colony. Average maximum distance from the colony of all 21 trips was $78.5( \pm 50.0) \mathrm{km}$, with nearly half of the trips exceeding $90 \mathrm{~km}$ from the colony. Mean maximum distance from the colony (range: 70.3-91.1 km) was similar among individuals (1-way ANOVA, $F_{3,17}$ $=0.18, \mathrm{p}=0.91$ ). Trip duration was variable, ranging from 9 to $159 \mathrm{~h}$, averaging $60.2( \pm 42.2) \mathrm{h}(\mathrm{n}=23)$. Mean trip duration did not differ significantly among individuals (1-way ANOVA, $F_{3,19}=1.61, \mathrm{p}=0.22$ ).

Five loop trips were clockwise and 6 were counterclockwise, with no consistency within individuals. Many trips ( $\mathrm{n}=7$ ) followed a figure-eight path, with 1 clockwise and 1 counterclockwise loop.

\section{Foraging trip duration and distance}

Twice-daily nest checks overestimated trip durations (41\% greater durations) compared to satellite data, especially for short trips (Table 4). Nest checks once per day, whether in the morning or evening, overestimated trip durations by 60 and $71 \%$, respectively. However, durations determined by nest checks were highly correlated $\left(\mathrm{r}^{2}=0.96\right)$ with durations determined by satellite.

For Magellanic penguins, maximum distance from the colony depended

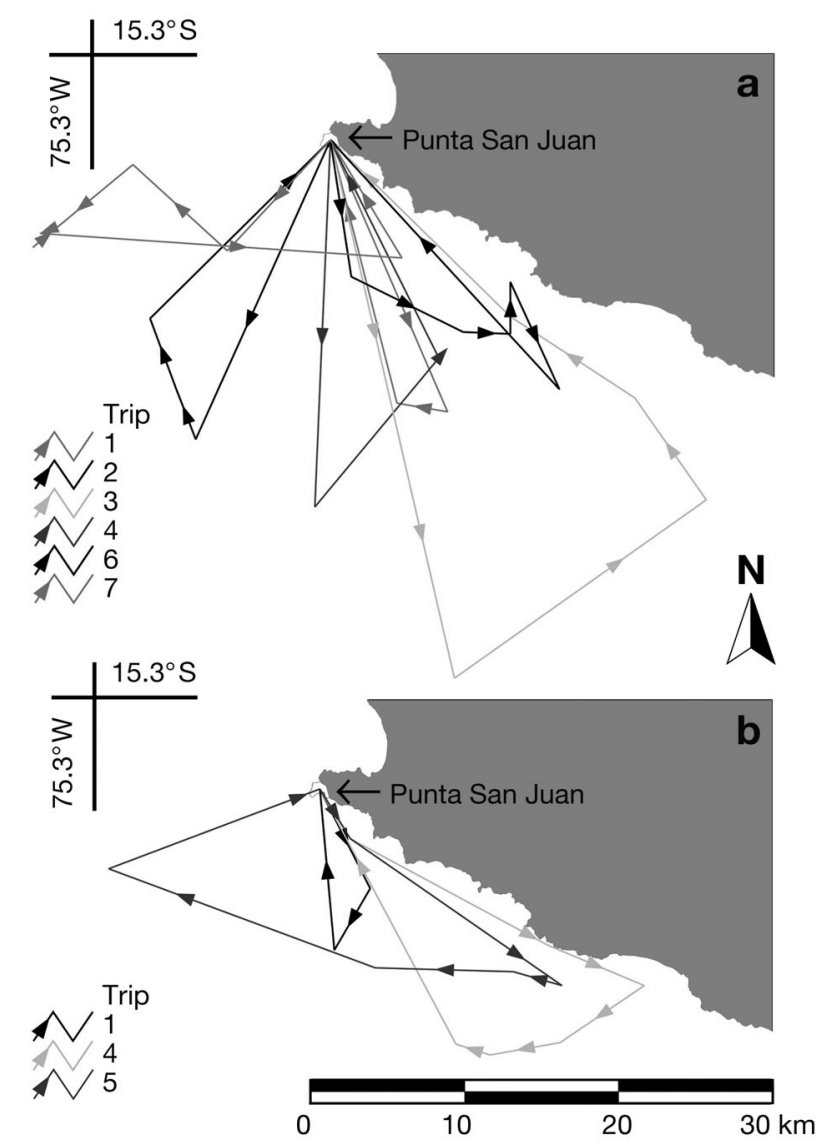

Fig. 2. Spheniscus humboldti. Foraging trips of 2 females breeding at Punta San Juan, Peru, July 2000. Only trips with at least 2 at-sea locations of Class 1 or better are included, and only locations of Class 1 or better were used to plot trips (see text). (a) Female 1; (b) Female 2
Table 3. Spheniscus humboldti. Foraging trips of 2 females breeding at Punta San Juan, Peru, 29 June to 22 July 2000, as determined by satellite telemetry and field checks of nest attendance. Only locations of Class 1 or better were used to calculate distances (see text). All distances in km. nc: not calculated be cause no Class 1 locations were received

\begin{tabular}{|ccccccc|}
\hline Trip no. & $\begin{array}{c}\text { Location } \\
\text { Class 1-3 }\end{array}$ & $\begin{array}{c}\text { Duration } \\
\text { (h) }\end{array}$ & $\begin{array}{c}\text { Max. } \\
\text { distance } \\
\text { from colony }\end{array}$ & $\begin{array}{c}\text { Min. } \\
\text { distance } \\
\text { traveled }\end{array}$ & $\begin{array}{c}\text { Max. } \\
\text { distance } \\
\text { from shore }\end{array}$ \\
\hline Female 1 & 1 & 6 & 28 & 19.3 & 59.9 & 18.9 \\
& 2 & 5 & 33 & 21.3 & 51.4 & 5.6 \\
& 3 & 4 & 39 & 35.0 & 87.2 & 25.3 \\
& 4 & 2 & 33 & 23.3 & 50.8 & 19.8 \\
& 5 & 0 & 36 & nc & nc & nc \\
& 6 & 3 & 41 & 20.6 & 44.5 & 19.7 \\
& 7 & 2 & 32 & 18.7 & 39.0 & 11.6 \\
& 8 & 1 & 15 & 9.7 & 19.4 & 4.4 \\
Female 2 & 1 & 2 & 27 & 10.1 & 21.2 & 6.9 \\
& 2 & 1 & 25 & 30.0 & 59.7 & 3.5 \\
& 3 & 1 & 26 & 7.3 & 14.5 & 6.9 \\
& 4 & 4 & 27 & 23.2 & 53.9 & 8.3 \\
& 5 & 4 & 25 & 19.5 & 61.0 & 12.7 \\
\hline
\end{tabular}



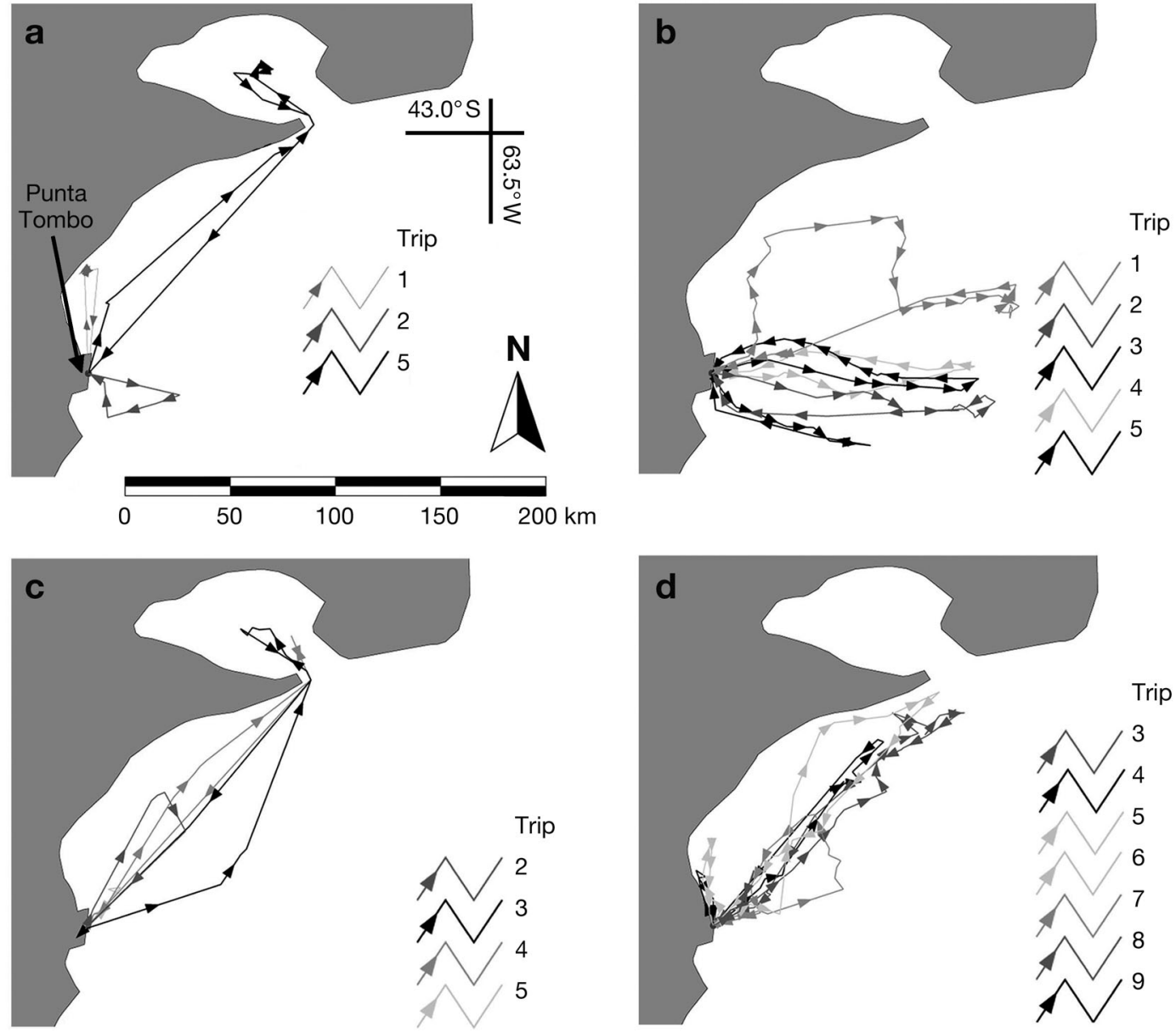

Fig. 3. Spheniscus magellanicus. Foraging trips of 4 females (a to d) breeding at Punta Tombo, Argentina, in November and December 1999. Only trips with at least 2 at-sea locations of Class 1 or better are included, and only locations of Class 1 or better were used to plot trips (see text)

strongly on trip duration (Fig. 4, Table 5). The penguins averaged nearly 1 additional $\mathrm{km}(0.70-0.94 \mathrm{~km})$ farther from the colony for each additional hour of trip duration. For each Magellanic penguin tracked during the early chick-rearing stage in 1999, trip duration was strongly correlated with maximum distance from the colony $\left(\mathrm{r}^{2}=0.84-0.98\right)$.

There was no relationship between trip duration and distance for Humboldt penguins (maximum distance from colony: $\mathrm{r}^{2}=0.41, F_{3,8}=1.87, \mathrm{p}=0.21$ ), perhaps because of the low frequency of locations received during trips that only lasted $30 \mathrm{~h}$ on average. All 5 trips of Female 2 lasted between 25 and $27 \mathrm{~h}$. With such a restricted range in duration, there was no relationship between distance and direction for that individual $\left(\mathrm{r}^{2}=\right.$ 0.19, $\mathrm{p}=0.47$ ). For Female 1, however, there was a significant relationship $\left(\mathrm{r}^{2}=0.60, \mathrm{p}=0.04, \mathrm{n}=7\right)$, with an increase of $0.68 \mathrm{~km}(\mathrm{SE}=0.25)$ per additional hour at sea.

\section{DISCUSSION}

\section{Foraging patterns}

Humboldt and Magellanic penguins, although closely related and similar in many respects, showed markedly different foraging patterns. Two Humboldt penguins tracked at Punta San Juan, Peru, took short trips and foraged close to the colony, with over $90 \%$ of all locations within a $25 \mathrm{~km}$ radius. In contrast, Magellanic penguins tracked at Punta Tombo, Argentina, took trips of more variable duration and foraged in diverse locations over a broad area, often far from the colony. Magellanic penguins provisioning small chicks (less than about $1 \mathrm{mo}$ old) foraged more than $150 \mathrm{~km}$ from the colony in some cases. Magellanic penguins foraged up to $300 \mathrm{~km}$ from the colony when provisioning older chicks, and sometimes more than $500 \mathrm{~km}$ from the colony during incubation. 
Table 4. Spheniscus magellanicus. Comparisons of trip duration derived from satellite locations and nest checks. Foraging trips $(n=71)$ of females were tracked by satellite from 1998 to 2002 during periods when the nests were checked twice per day. Durations based on nest checks were derived post hoc from nest attendance recorded at the different nest check regimes. Regression statistics are from regressions of nest checks with satellitedetermined duration

\begin{tabular}{|lcccc|}
\hline Method & $\begin{array}{c}\text { Mean (SD) } \\
\text { duration (h) }\end{array}$ & $\mathrm{r}^{2}$ & Intercept & Slope \\
\hline Satellite tracking & $45.0(47.9)$ & - & - & - \\
Twice-daily nest checks & $63.5(45.9)$ & $0.96^{\mathrm{a}}$ & $21.09^{\mathrm{a}}$ & $0.93^{\mathrm{a}}$ \\
Morning-only nest checks & $72.1(59.4)$ & 0.78 & 17.04 & 1.26 \\
Evening-only nest checks & $77.1(45.3)$ & 0.78 & 37.36 & 0.92 \\
a One trip was excluded because the bird was not seen again until long \\
after the breeding season. When this trip was not excluded, $\mathrm{r}^{2}=0.76$, \\
intercept = 29.44, slope = 0.87
\end{tabular}

tures (MacIsaac et al. 1985), creates reliable concentrations of food for Humboldt penguins close to shore. Punta San Juan appears to be a center of distribution of the anchoveta Engraulis ringens, a major prey species of Humboldt penguins (Paredes et al. 2002), even during El Niño conditions (Mathisen 1989). By contrast, Magellanic penguins breeding at Punta Tombo forage over the wide Patagonian shelf, where productivity is locally concentrated by seasonal fronts spread over a larger area (Acha et al. 2004). We hypothesize that oceanographic productivity patterns have led to Humboldt penguins feeding inshore and close to the colony, and Magellanic penguins feeding offshore and farther from the colony. Local ocean productivity

These results are consistent with other studies of these 2 species. Croxall \& Davis (1999) classified Magellanic penguins as offshore feeders and Humboldt penguins as inshore feeders. Magellanic penguins tracked by satellite and global location sensor tags during incubation typically foraged more than $100 \mathrm{~km}$, and sometimes as much as $600 \mathrm{~km}$ from various colonies in Argentina (Wilson et al. 1995, 2005, Boersma \& Parrish 1999, Stokes \& Boersma 1999). Satellite tracking, along with trip duration and swim speed data, from colonies in Chile indicate that breeding Humboldt penguins forage closer to their colonies than Magellanic penguins, generally within about $50 \mathrm{~km}$, except under strong El Niño conditions (Culik et al. 2000). The short foraging-trip durations of Humboldt penguins in Peru also suggest that they forage close to their nests (Taylor et al. 2001; see also below).

Penguins forage in areas of high productivity, where their prey is concentrated. The exceptionally narrow continental shelf along the Pacific coast of South America, with upwelling centers tied to topographic fea-

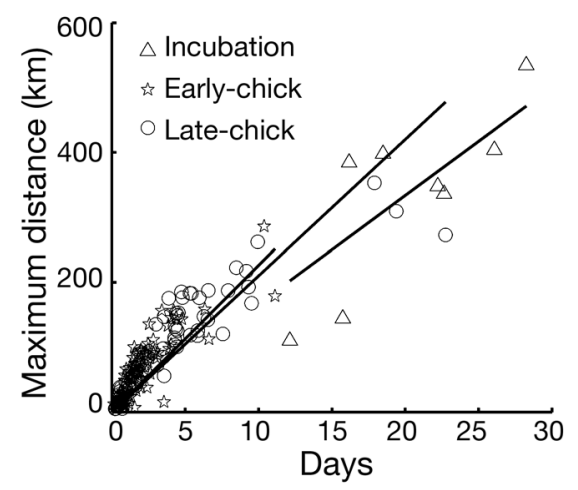

Fig. 4. Spheniscus magellanicus. Maximum distance from the colony as a function of trip duration in all 3 stages of the breeding season. Incubation: 8 trips by 8 females; early-chick: 96 trips by 20 females; late-chick: 75 trips by 17 females also influences foraging distances in Magellanic penguins breeding at different colonies in Argentina (Wilson et al. 2005, P. D. Boersma et al. unpubl.).

\section{Trip duration as an indicator of foraging distance and marine conditions}

Magellanic penguin foraging trip duration was highly correlated with maximum distance from the colony. On average, each additional hour a penguin was gone from the nest on a foraging trip increased foraging range by nearly $1 \mathrm{~km}$ (Fig. 4). Wilson et al. (1995) found no relationship between trip duration and distance from the colony in Magellanic penguins breeding about $225 \mathrm{~km}$ north of Punta Tombo; however, that study used global location sensors with much lower resolution (estimated accuracy 40-150 km; Wilson et al. 1995) than satellite-tracking data. In other satellitetracking studies, maximum distance from the colony was correlated with trip duration in king penguins Aptenodytes patagonicus (Wienecke \& Robertson 2002) and royal penguins Eudyptes schlegeli (Hull et al. 1997), and total distance traveled was significantly correlated with trip duration in king (Wienecke \&

Table 5. Spheniscus magellanicus. Relationship between maximum distance from the colony and trip duration at Punta Tombo, Argentina, over 5 yr. Slopes represent the additional distance $(\mathrm{km})$ from the colony for each hour of absence from the nest

\begin{tabular}{|lcccc|}
\hline Stage & Slope (SE) & $\mathrm{df}$ & $t$ & $\mathrm{p}$ \\
\hline Incubation & $0.70(0.06)$ & 7 & 11.56 & $<0.0001$ \\
Early-chick & $0.94(0.06)$ & 75 & 14.88 & $<0.0001$ \\
Late-chick & $0.87(0.04)$ & 58 & 21.42 & $<0.0001$ \\
\hline
\end{tabular}


Robertson 2002), Adélie Pygoscelis adeliae (Clarke et al. 1998), and African penguins Spheniscus demersus (Heath \& Randall 1989).

The strength and constancy of the relationship between distance from the colony and duration of the foraging trip suggests that trip duration during breeding provides an accurate estimator for determining penguin foraging distance. Relative to satellite tracking or similar techniques, this surrogate measure of foraging distance is low-cost, logistically simple, minimally disturbing, and could be usefully applied to Humboldt penguins and other species. While this method provides no information on the direction the birds travel and hence cannot show exact foraging locations, for species that forage close to breeding colonies, the possible foraging areas must be within a circle around the colony equal in radius to the maximum foraging distance from the colony.

Our tracking results are consistent with the inshore nature of Humboldt penguin foraging. Additional evidence is provided by nest absence periods for 15 female Humboldt penguins with young chicks in November 1999 (Taylor et al. 2001, S. S. Taylor pers. comm.). Trips averaged $20.3( \pm 4.1) \mathrm{h}$ (range $=$ 4.4-52.2 h). If the relationship between distance and duration for Humboldt penguin trips is similar to that for Magellanic penguins, the maximum distance from the colony for the Humboldt penguins in that study averaged $19 \mathrm{~km}(4-49 \mathrm{~km})$. This is probably an underestimate for the shorter trips, since the slope of the relationship is steeper for short trips $(<2 \mathrm{~d})$ than for longer trips (Fig. 4).

Trip duration, as an indicator of trip distance, also provides a means of monitoring marine conditions and the quality of foraging conditions for penguins. The tight relationship between distance and trip duration suggests that penguins swim away from the colony until they encounter food, forage until they have enough for the chicks, and then immediately return. Thus, foraging trip duration may indicate distance from the colony of prey concentrations.

Distance to food appears to be a key determinant of penguin reproductive success (Davis \& Renner 2003). For example, Magellanic penguins at Punta Tombo travel farther for food and have lower fledging success than those nesting at New Island in the Falkland Islands, where foraging trips are shorter (Boersma et al. 2002). Similarly, little penguins Eudyptula minor raising chicks at Motuara (New Zealand) are away from the nest much longer, presumably because they must travel farther to food than those that breed at Oamaru, where trips are shorter and fledging success is much higher (Numata et al. 2000). Similar patterns of extended foraging trips and lowered pup survival in response to decreased food availability have been re- ported for a variety of pinniped species (e.g. Gentry \& Kooyman 1986). Longer foraging trips, whether caused by scarcer or more distant food, require increased energy expenditure and increase the likelihood of chick starvation. Foraging trip duration at equivalent stages of the breeding season should be an effective indicator of change in marine conditions over time and may prove useful for quantifying the effects of climate change and management policies on marine ecosystems.

Satellite tracking allows relatively precise determination of trip duration, but because of its expense, it is not widely available to biologists and wildlife managers. In addition, concerns about negative effects on penguin behavior or breeding success may make deployment of transmitters undesirable, especially for species of conservation concern (Wilson \& McMahon 2006). An inexpensive and minimally disturbing approximation of foraging trip duration may be obtained through nest checks. Durations determined by nest checks were highly correlated with durations determined by satellite, suggesting that this measure could be a sensitive indicator of changes in foraging activity and a useful comparative measure. Combining nest checks with a few satellite transmitters could reduce the expense and disturbance of a large-scale telemetry study, while providing some information on foraging locations and a large amount of data on foraging distance.

\section{Conservation strategies}

The contrasting foraging patterns of the Magellanic and Humboldt penguins indicate that conservation strategies for the 2 species must address different spatial scales. For example, an area of approximately $1200 \mathrm{~km}^{2}$ within a $25 \mathrm{~km}$ radius around Punta San Juan (Fig. 1) encompassed $90 \%$ of the Humboldt penguin locations we recorded, while the same proportion of Magellanic penguin locations was spread over an area more than 10 times as large. A single MPA may be adequate to protect breeding Humboldt penguins except perhaps during strong El Niño years (Culik et al. 2000). Such an approach would fail to protect Magellanic penguins, where larger-scale ocean zoning that includes spatially and seasonally flexible protection is more likely to be effective.

Regardless of which approach is taken to protect marine species, the design of effective conservation measures requires an understanding of the species' use of the marine environment. Our need for information about species will continue to outstrip what is available, and it is unrealistic to expect that we can undertake detailed studies for every imperiled species. 
More common or better-studied species such as Magellanic penguins offer practical insights into the conservation of less-studied or more endangered species, such as Humboldt penguins. Furthermore, development of practical and inexpensive surrogates for more costly and potentially disturbing techniques such as animal tracking will be important for conservation of endangered species.

Acknowledgements. We thank M. Roca, G. Mori, and N. Hillgarth for help in the field and S. Taylor for access to unpublished Humboldt penguin nest-attendance data. Research was funded by grants from Friends of Woodland Park Zoo and Portland Zoo, and by the Pew Fellows Program in marine conservation, an initiative of the Pew Charitable Trusts in partnership with the New England Aquarium. The Wildlife Conservation Society helped with logistical arrangements and funding, as did the Wadsworth Endowed Chair in Conservation Science. We thank S. Moore, E. Skewgar, and 3 anonymous reviewers for improving the manuscript.

\section{LITERATURE CITED}

Acha EM, Mianzan HW, Guerrero RA, Favero M, Bava J (2004) Marine fronts at the continental shelves of austral South America: physical and ecological processes. J Mar Syst 44: 83-105

Bannasch R, Wilson RP, Culick B (1994) Hydrodynamic aspects of design and attachment of a back-mounted device in penguins. J Exp Biol 194:83-96

Boersma D, Parrish J (1999) Limiting abuse: marine protected areas, a limited solution. Ecol Econ 31:287-304

Boersma PD, Stokes DL, Yorio PM (1990) Reproductive variability and historical change of Magellanic penguins (Sphensicus magellanicus) at Punta Tombo, Argentina. In: Davis LS, Darby JT (eds) Penguin biology. Academic Press, San Diego, CA, p 13-44

Boersma PD, Stokes DL, Strange IJ (2002) Applying ecology to conservation: tracking breeding penguins at New Island South Reserve, Falkland Islands. Aquat Conserv Mar Freshw Ecosyst 12:63-74

Clarke J, Manly B, Kerry K, Gardner H, Franchi E, Corsolini S, Focardi S (1998) Sex differences in Adélie penguin foraging strategies. Polar Biol 20:248-258

Crawford RJM, Jahncke J (1999) Comparison of trends in abundance of guano-producing seabirds in Peru and southern Africa. S Afr J Mar Sci 21:145-156

Croxall JP, Davis LS (1999) Penguins: paradoxes and patterns. Mar Ornithol 27:1-12

Culik B, Hennicke J, Martin T (2000) Humboldt penguins outmanoeuvring El Niño. J Exp Biol 203:2311-2322

Davis LS, Renner M (2003) Penguins. Yale University Press, New Haven, CT

García-Borboroglu P, Boersma PD, Ruoppolo V, Reyes L and 5 others (2006) Chronic oil pollution harms Magellanic penguins in the Southwest Atlantic. Mar Pollut Bull 52: 193-198

Gentry RL, Kooyman GL (eds) (1986) Fur seals: maternal strategies on land and at sea. Princeton University Press, Princeton, NJ

Heath RGM, Randall RM (1989) Foraging ranges and move- ments of jackass penguins (Spheniscus demersus) established through radio telemetry. J Zool 217:367-379

Hull CL, Hindell MA, Michael K (1997) Foraging zones of royal penguins during the breeding season, and their association with oceanographic features. Mar Ecol Prog Ser 153:217-228

Hyrenbach KD, Forney KA, Dayton PK (2000) Marine protected areas and ocean basin management. Aquat Conserv Mar Freshw Ecosyst 10:437-458

IUCN (International Union for Conservation of Nature and Natural Resources) (2003) Red list of threatened species. Available at: www.redlist.org, 13 July 2004

Luna-Jorquera G, Garthe S, Sepulveda F, Weichler T, Vasquez J (2000) Population size of Humboldt penguins assessed by combined terrestrial and at-sea counts. Waterbirds 23:506-510

MacIsaac JJ, Dugdale RC, Barber RT, Blasco D, Packard TT (1985) Primary production cycle in an upwelling center. Deep-Sea Res 32:503-529

Majluf P, Babcock EA, Riveros JC, Schreiber MA, Alderete W (2002) Catch and bycatch of sea birds and marine mammals in the small-scale fishery of Punta San Juan, Peru. Conserv Biol 16:1333-1343

Mathisen OA (1989) Adaptation of the anchoveta (Engraulis ringens) to the Peruvian upwelling system. In: Pauly D, Muck P, Mendo J, Tsukayama I (eds) The Peruvian upwelling ecosystem: dynamics and interactions. ICLARM Conf Proc, Instituto del Mar del Peru (IMARPE), Callao, p 220-234

Numata M, Davis LS, Renner M (2000) Prolonged foraging trips and egg desertion in little penguins (Eudyptula minor). N Z J Zool 27:277-289

Paredes R, Zavalaga CB (2001) Nesting sites and nest types as important factors for the conservation of Humboldt penguins (Spheniscus humboldti). Biol Conserv 100:199-205

Paredes R, Zavalaga CB, Boness DJ (2002) Patterns of egg laying and breeding success in Humboldt penguins (Spheniscus humboldti) at Punta San Juan, Peru. Auk 119: 244-250

Sall J, Creighton L, Lehman A (2005) JMP statistics, 3rd edn. SAS Institute Inc. and Thomson, Belmont, CA

Simeone A, Bernal M, Meza J (1999) Incidental mortality of Humboldt penguins Spheniscus humboldti in gill nets, central Chile. Mar Ornithol 27:157-161

Stokes DL, Boersma PD (1999) Where breeding Magellanic penguins Spheniscus magellanicus forage: satellite telemetry results and their implications for conservation. Mar Ornithol 27:59-65

Taylor SS, Leonard ML, Boness DJ, Majluf P (2001) Foraging trip duration increases for Humboldt penguins tagged with recording devices. J Avian Biol 32:369-372

Wienecke B, Robertson G (2002) Foraging area of king penguins from Macquarie Island in relation to a marine protected area. Environ Manag 29:662-672

Wilson RP, McMahon CR (2006) Measuring devices on wild animals: What constitutes acceptable practice? Front Ecol Environ 4:147-154

Wilson RP, Scolaro JA, Peters G, Laurenti L, Kierspel M, Gallelli H, Upton J (1995) Foraging areas of Magellanic penguins Spheniscus magellanicus breeding at San Lorenzo, Argentina, during the incubation period. Mar Ecol Prog Ser 129:1-6

Wilson RP, Scolaro JA, Grémillet D, Kierspel MAM and 8 others (2005) How do Magellanic penguins cope with variability in their access to prey? Ecol Monogr 75:379-401

Submitted: May 18, 2005; Accepted: August 25, 2006

Proofs received from author(s): April 5, 2007 